\title{
ESTUDIOS
}

\section{Situación de Julio Cortázar}

Dentro del desarrollo de la nueva novela hispanoamericana la obra de Julio Cortázar forma la piedra angular que sostiene los dos contrafuertes del arco estructurado, hacia uno de sus lados, por las obras realistas de Carlos Fuentes y Mario Vargas Llosa, y hacia el otro por la narrativà fantástica y de realismo mágico de Juan Rulfo, José María Arguedas y Gabriel García Márquez. Las dos tendencias las une, de manera brillante, Julio Cortázar.

La corriente narrativa social, renovada por los escritores de la Revolución mexicana y continuada por los indigenistas y los autores de novelas telúricas o de contenido político, obtiene madurez con Fuentes y Vargas Llosa, en novelas como La región más transparente (1958), La muerte de Attemio Cruz (1962), La ciudad y los perros (1963) y Conversación en la catedral (1969). La literatura fantástica, iniciada por Borges con la Historia universal de la infamia en 1935 y tan brillantemente cultivada en Ficciones (1944) y $\mathrm{El}$ Alepb (1949), la continúan Bio y Casares, Anderson-Imbert, Juan José Arreola y Julio Cortázar en el Bestiario y algunos otros cuentos. La narrativa magicorrealista, admirablemente cultivada por Alejo Carpentier (Ecue-Yamba-O, 1933; El reino de este mundo, 1949; Los pasos perdidos, 1953) y Miguel Angel Asturias (Leyendas de Guatemala, 1930; Hombres de maiz, 1949), tiene sus representantes dentro de la nueva novela en Rulfo, Arguedas y García Márquez en novelas como Pedro Páramo (1955), Los rios profundos (1958) y Cien años de soledad (1967) ${ }^{1}$.

Julio Cortázar es el novelista hispanoamericano de esta generación que mejor logra integrar las corrientes anteriores y producir una obra narrativa que, sin ser indiferente a los problemas sociales, es rica en virtudes artísticas. Nos referimos, por supuesto, a la obra madura de

1 Para un estudio de este último tema véase nuestro artículo "El realismo mágico y la nueva natrativa hispanoamericana" en Donald W. Bleznick (ed.), Variaciones interpretativas en torno a la nueva nartativa bispanoamericana (San. tiago, Chile, 1972), pp. 49-62. 
Cortázar, a la obra producida a partir de 1959, fecha de Las armats secretas; porque es en el cuento "El perseguidor", de esa colección, donde hày que buscar las raíces del cambio en el arte de la ficción en Cortázar.

Antes de 1959 Cortázar había publicado tres libros de ficciones, Los reyes (1949), Bestiario (1951) y Findl del juego (1956), todavia bajo la influencia de Borges. En Los reyes recoge el tema del Minotauro, ya trabajado por Borges en el cuento " $L a$ casa de Asterión"; ambas obras fueron publicadas primero en Los Anales de Buenos Aires, la de Borges en junio (núm. 15-16) y la de Cortázar en diciembre (núm. 20-22). La estructura dramática (en cinco escenas) del poema en prosa de Cortázar es, sin embargo, original, y en la forma se aproxima más a obras como la Ifigenia cruel de Alfonso Reyes y El nacimiento de Dionisos de Pedro Henríquez Ureña que al cuento de Borges. Si bien el tema y algunos motivos en el cuento de Borges y en Los rejes son idénticos, el tratamiento del material es distinto. En Borges el punto de vista es el del Minotauro, quien nos revela sus estados de conciencia. Sabemos que no siente ser prisionero, ya que en su. casa, el laberinto, no hay puertas cerradas;" como hijo de reyes, se siente superior al vulgo; aunque "libera de todo mal" a las doncellas y donceles que recibe en tributo, no lo hace por crueldad; además, espera que llegue su redentor. Borges, deseando mantenerse dentro del rígido esquema que su estética le impone para el cuento corto, no dramatiza el encuentro entre Teseo y Minotauro; el resultado del encuentro (la muerte de Minotauro) apenas si se insinúa en el epílogo, donde Teseo le dice a Ariadna que el prisionero apenas se defendió; esto debido a que la función de ese epílogo es otra: revelarnos la identidad del narrador, incógnita que se mantiene hasta la última línea.

En Los reyes el Minotauro tampoco se defiende; pero por otras razones. Néstor García Canclini nos dice que esta obra de Cortázar "gita alrededor de dos temas —el laberinto y lo monstruoso". ${ }^{3}$ Hay que subrayar, sin embargo, que el tema del laberinto no tiene en Los reyes el significado que le da Borges en "La casa de Asterión". Para Borges el laberinto es símbolo del universo; en Cortázar el laberinto es simbolo de lo monstruoso, es la prisión de un monstruo, el Minotauro. Dice Minos: "El no es nuestro, un artificio. ¿Sabes de quién es hermano?

2 Este tema del prisionero libre lo trata Bioy-Casares en la novela Plan de evasión (1945).

${ }^{3}$ Cortázar, una antropología poética (Buenos Aires: Editorial Nova, 1968), p. 20 . 
Del laberinto. De su cárcel misma. ¡Oh caracol horrendo! Hermano de su jaula, de su prisión de piedra. Un artificio, mira, igual que su prisión. Dédalo los hizo a ambos, astuto ingeniero". "El tema del laberinto, así, se convierte en el tema de lo monstruoso y no, como en Borges, en el tema del universo sin fin. El laberinto, para Cortázar, es mons: truoso para los monstruos. Dice Ariadna: "Nadie sabe qué mundo multiforme o qué multiplicada muerte llenan el labetinto. Tú tienes el tuyo, poblado de desoladas agonías. El pueblo lo imagina concilio de divinidades de la tierra, acceso al abismo sin orillas. Mi laberinto es claro y desolado, con un sol frío y jardines centrales donde pájaros sin voz sobrevuelan la imagen de mi hermano dormido junto a un plinto" (p. 20).

El tema de lo monstruoso, que se ha de repetir con insistencia en la narrativa posterior, sí es original de Cortázar; reaparece en algunos de los cuentos del Bestiario, en "El perseguidor", en "Las puertas del cielo" y en otros cuentos, lo mismo que en algunas escenas de las novelas. La clave del tema de lo monstruoso la encontramos en estas palabras del Minotauro a Teseo: "Mira, sólo hay un medio para matar los monstruos: aceptarlos" (p. 64).

Dijimos que el minotauro de Cortázar, como el de Borges, no se defiende de Teseo. El de Borges lo hace porque cree que la muerte libera; el de Cortázar, por razones más humanas: está enamorado de su hermana Ariadna y se deja matar al saber que le ha proporcionado a Teseo el modo de salir del laberinto; no sabe que su hermana, también enamorada, lo hizo para facilitarle a él la salida con el hilo que le llevaba Teseo. Este tema del incesto, que ha de aparecer en obras posteriores de Cortázar ("Casa tomada", por ejemplo), es fundamental para comprender lo que de original hay en el mito de Minotauro según se interpreta en Los reyes. El autor mismo se ha quejado de que su interpretación del mito del Minotauro no ha recibido la atención que merece. En la entrevista con Luis Harss dijo: "Es decir, la versión es totalmente opuesta a la clásica". Y añade Harss: "Aunque el cambio no parece haber impresionado mayormente al público literario argentino. Nadie se enteró casi, dice Cortázar. A pesar de que Borges, que conocia el texto, lo había publicado ya en su revista Los Anales de Buenos Aires, cuando apareció Los reyes fue recibido 'con un silencio absoluto y cavernoso" "s En esa entrevista, Cortázar no insiste en el tema del inces-

+ Julio Cortázar, Los reyes (Buenos Aires: Editorial Sudamericana, 1970), p. 14. Citarnos por esta edición.

5 Los nuestros (Buenos Aires: Sudamericana, 1966), p. 264. 
to; más bien, le da énfasis al conflicto entre Teseo y el Minotauro como representantes de lo convencional y lo extraordinario. Dice: "Pero el enfoque del tema es bastante curioso, porque se trata de una defensa del Minotauro. Teseo es presentado como el héroe standard, el individuo sin imaginación y respetuoso de las convenciones, que está allí con una espada en la mano para matar a los monstruos, que son la excepción de lo convencional. El Minotauro es el poeta, el ser diferente de los demás, completamente libre. Por eso lo han encerrado, porque representa un peligro para el orden establecido" (Pp. 263-264). Creemos que la originalidad de Cortázar en esta primera obra narrativa, en cuan. to a la interpretación del mito del Minotauro, es suficiente para rechazar juicios como el siguiente: "En su primera época [Cortázar] fue una especie de esteta borgiano cuya sombra lo persigue todavía". ${ }^{6}$ En Borges los personajes son simples figuras alegóricas que sirven para encarnar sus ideas filosóficas; en Cortázar, los personajes son seres humanos. El amor de Ariadna por Minotauro, y el sacrificio de éste, los humaniza. Ariadna justifica la conducta del Minotauro diciendo: "Cómo podría vivir sin comer? La cólera nació del primero que tuvo hambre" ( $p$. 18). Si es verdad que en Los reyes aparecen algunas ideas borgianas, como la de la identidad de los personajes (Minos es Teseo), también es cierto que el elemento humano es lo que predomina en Cortázar, mientras que en Borges es lo metafísico lo que resalta.

Cortázar, que no se repite, no ha vuelto a los temas clásicos o al estilo y la estructura dramática de Los reyes. El mismo ha dicho: "En realidad Los reyes es una obra con la que sigo profundamente encariñado, pero no tiene nada o muy poco que ver con lo que escribí después. Tiene un estilo de esteta, muy refinado, pero el lenguaje en el fondo es muy tradicional. Una especie de mezcla de Valéry y SaintJohn Perse" (Harss, p. 265). Sin embargo, ya aparecen en ese libro, como hemos visto, algunos temas (como el del incesto, o el del monstruo), algunos motivos (el laberinto, el héroe standard) y algunas ideas que han de ser elaboradas en obras posteriores.

Si bien el Bestiario, que se publica en 1951, marca un gran adelanto en el desarrollo de Cortázar como narrador, no fue recibido como gran acontecimiento en el mundo de las letras hispanoamericanas. Ya para ese año Borges había publicado Ficciones y El Alepb y por tanto, ¿quién iba a entusiasmarse con esos ocho cuentos en los que nada pasa, en los que se trata de mostrar — según la nota de la solapa- la sombra de la

- Harrs, pp. 254-255. 
realidad, ; cuando se podía gozar con los juegos laberínticos de Borges? Cortázar, sin embargo, tenía fe en que lo suyo era diferente, original. "A partir de un momento dado, digamos 1947, yo estaba completamente seguro de que casi todas las cosas que mantenía inéditas eran buenas, y que algunas de ellas incluso eran muy buenas. Me refiero, por ejemplo, a uno o dos de los cuentos de Bestiario. Yo sabía que cuentos así no se habian escrito en español, en mi país por lo menos. Había otros. Estaban los admirables cuentos de Borges. Pero yo hacía otra cosa" (Harss, P. 264). Y tiene razón Cortázar. Antes de 1951 sólo Juan José Arteola había publicado, en México, su Varia invención (1949), libro que, aunque distinto al Bestiario, aporta una nueva manera de relatar, desconocida en la literatura hispanoamericana; estos dos libros, y los dos de Borges, pueden ser considerados como fundamentales en el desarrollo de la nueva narrativa. Cabe preguntar, ¿qué novedades aporta la obra de Cortázar? En primer lugar, la ambigüedad, considerada por Carlos Fuentes como una de las características principales del nuevo relato. "Pienso -dice- que es más cercano a la verdad entender, en primera instancia, el conflicto de la literatura hispanoamericana en relación con ciertas categorías concretas del quehacer literario o, mejor aún, como la conquista de esas categorias, tradicionalmente ausentes en nuestra narrativa: mitificación, alianza de imaginación y crítica, ambigüedad, humor y parodia, personalización. Que, al cabo, este haz de categorias culmine en un nuevo sentido de bistoricidad y de lenguaje es lo que me propongo demostrar en las notas dedicadas a Vargas Llosa, Carpentier, García Márquez y Cortázar".s Ambiguos son los cuentos del Bestiario, y sobre todo "Casa tomada", "Omnibus" y "Lejana". La mitificación la encontramos en "Las puertas del cielo" o el humor y la parodia en "Cefalea" y en "Cartas a una señorita en París". La categoría que todavia no aparece es la crítica, a no ser que queramos ver en "Casa tomada" una velada referencia al peronismo.

Un año antes de que apareciera el Bestiario Cortázar había publicado en México un ensayo, "Situación de la novela", sobre teoria literaria $y$, en particular, sobre estética narrativa, en el cual nos dice que la li-

7 La nota, firmada D. D., sin duda es de Daniel Devoto, amigo de Cortázar y quien había publicado la primera edición de Los reyes (Ver Harrs, p. 265).

8 Carlos Fuentes, La nueva novela bispanoamericana (México: Joaquín Mortiz, 1969), p. 24.

9 Sobre este libro ver Martha Paley de Francescato, "El Bestiario de Julio Cortázar, enriquecimiento de un género". Tesis doctoral inédita, Universidad de Illinois, Urbana, 1970. "Casa tomada" se había publicado en Los Anales de Buenos Aires, I, 11 (1946), 13-18. 
teratura puede ser considerada como "una empresa de conquista de la realidad". ${ }^{10}$ Desde el punto de vista del desarrollo literario de Cortázar la trayectoria evoluciona del poema al poema en prosa, al cuento, a la novela. Mas su "historia" literaria, como él mismo apunta, consistiria "no tanto en la evolución de las formas como en las direcciones y estrategias de su empresa de conquista" (Ibid.). Si en Lós reyes se apodera del mito clásico, en Bestiario pasa a conquistar la realidad circundante en el cuento "Las puertas del cielo", donde logra apoderarse de cierto sector del mundo porteño. Como estrategia usa la ficha documental (técnica que ha de aparecer también, aunque brevemente, en Rayuela) y en los diálogos ya tecrea, se apodera) del lenguaje de los porteños de ese sector (Mauro, Celina). El narrador, el doctor Marcelo Hardoy, es "un abogado que no se conforma con el Buenos Aires forense o musical o hípico, y avanza todo lo que puede por otros zaguanes". ${ }^{11} \mathrm{Si}$ es verdad que reaparece el tema de lo monstruoso, introduce también el tema del caos, que ha de desarrollar en las novelas. El Santa Fe Palace es "el caos, la confusión resolviéndose en un falso orden: el infierno y sus círculos" (p. 127). Lo monstruoso lo encontramos en los personajes que frecuentan ese cabaré. "Iba a esa milonga - dice el abogado- por los monstruos, y que no sé de otra donde se dén tantos juntos" (p. 129). Celina, la protagonista, es hasta cierto punto representante de ese arquetipo; sólo que, como Minotauro, tiene que estar en su laberinto (la milonga) para que aflore ese aspecto de su carácter. "Entonces - piensa Marcelo durante su visita con Mauro al Santa Fe Palace - me volvió la idea de que Celina había sido en cierto modo un monstruo como ellos, sólo que fuera y de día no se notaba como aqui" (p. 133). Por medio de esa simbiosis Cortázar capta ágilmente no sólo la sicologia de los personajes, sino también la esencia de la milonga porteña.

Los reyes y Bestiario son los dos libros que Cortázar publica en Buenos Aires antes de emigrar en 1951 para exilarse voluntariamente en París. Antes de partir escribe un ciclo de poemas, y luego en Paris, en 1955, el titulado "La patria". "En los últimos tiempos me he preguntado - dice Cortázar- porqué casi nunca quise publicar versos, yaque he escrito tantos; será, pienso, porque me siento menos capaz de juzgarme por ellos que por la prosa, y quizá por un placer perverso de

10 Julio Cortázar, "Situación de la novela", Cuadernos Americanos, IX, 14 (julio-agosto, 1959), pp. 225-243; la cita en la p. 223.

11 Julio Cortázar, Bestiario (Buenos Aires: Editorial Sudamericana, 1967), p. 121. Citamos por esta edición. 
guardar lo que quizá es más mio. [...] Enemigo de confidencias directas, estos poemas mostrarán un estado de ánimo en la época en que decidí marcharme del país. "La patria" lo resume, años después, con algo que será acaso mal entendido; para mí, detrás de tanta cólera, el amor está alli desnudo y dado como el río que me llevó tan lejos". ${ }^{12}$

Han de pasar cinco años antes de que publique su siguiente libro, Final del juego (1956), en la colección "Los Presentes", que en México había iniciado Juan José Arreola. Nos dice Harss, al comentar este libro, que Cortázar seguía "entreteniéndose escrupulosamente con sus sortilegios. Se repetía, y comenzaba a dudar de su progreso" (p. 258). Estos cinco años, años de dudas $\mathrm{y}$ de angustia, pero también de búsqueda y renovación para Cortázar, son años de gran fermento en el desarrollo de la novela hispanoamericana. Juan José Arreola publica el Confabulario (1952), Rulfo sus dos obras (El llano en llamas, 1953; Pedro Páramo, 1955), Carpentier Los pasos perdidos (1953) y El acoso (1956), Onetti Los adioses (1954), Fuentes el primer libro de cuentos (Los dias enmascarados, 1954), y García Márquez la primera novela ( La bojarasca, 1955). Cortázar contribuye con los nueve cuentos de Fital del juego, algunos de los cuales ("Axolotl", "La noche boca arriba", "Los venenos", "Torito") son memorables, tanto por los procedimientos como por los temas y el lenguaje. Si es cierto que la base de esos cuentos es la experiencia personal, también es verdad que esa experiencia ha sido trascendida al someterla a los rigores de la forma artística.

El cuento "Torito" puede ser considerado como de transición hacia una nueva manera narrativa en Cortázar, ya que ahí encontramos la historia mental de un boxeador caído en la enfermedad y la miseria, contada desde adentro, en primera persona; las palabras del Torito fluyen como torrente desordenado. Anticipan, en cierto modo, la trágica historia de Johnny en "El perseguidor", uno de los cinco cuentos recogidos en Las armas secretas (1959), y que representa la independencia total de la influencia borgiana. Si bien Torito es un púgil argentino $y$ Johnny un saxofonista norteamericano, hay mucho de común entre los dos; "mientras mascullaba "Torito" para este disco —dice Cortázar-, pensé que fue escrito en 1952, veinte años después de los espisodios que un púgil tuberculoso rememora en un hospital de Córdoba, y que

12 Julio Cortázar La vuelta al dia ent ochenta mundos (México: Siglo Veintiuno Editores, 1967), p. 194. Se reproducen las poesías citadas. No hay que olvidar que el primer libro de Cortázar fue una colección de sonetos, Presencia (Buenos Aires: El Bibliófilo, 1938), publicado con el seudónimo "Julio Deniss". 
en mi pieza de París sólo conté con una memoria que me iba alcanzando a su manera tanto nombre y pasaje que entonces le acepté confiado. Hoy, otros veinte años después, dudo de estas supuestas certezas, y me gustaria que algún historiador argentino del noble arte verificara los datos". ${ }^{13} \mathrm{El}$ mismo Cortázar nos da algunos datos históticos; el púgil es, por supuesto Justo [Antonio?] Suárez; el patrón, Pepe Lectoure; el negro, Bruce Flowers; el Brujo, Juan Carlos Casalá; el Tani Loayza, un chileno; el "Yoni" del auto rojo un yanqui llamado Herman, y el que acabó con el Torito Billy Petrolle, "El expreso de Fargo". A Tala, dice Cortázar, "creo que lo inventë". En "El perseguidor" hay menos personajes históricos; pero el protagonista, Johnny Carter, ha salido de la realidad; en cambio Bruno, su biógrafo, es sin duda un personaje inventado, como Tala. Pero Bruno en este cuento es el narrador y vemos la personalidad de Johnny sólo desde su perspectiva.

El cambio del personaje imaginado -que no abandona por completo, como lo prueban los que aparecen en las Historias de cronopios $y$ de famas (1962) - al personaje de carne y hueso como el Torito $y$ Johnny también lo encontramos en Los premios (1960). Esta primera novela representa la conquista de una nueva técnica - que se ha de repatir en Rayuela (1963) y en el Libro de Manuel (1973) - que consiste en reunir un grupo de personajes que forman una figura, y poco a poco ir desarrollando las relaciones mutuas por medio del intercambio social, que se logra a través del diálogo. En Los premios se reune a un grupo de personas representativas de la sociedad argentina, si bien la figura se ha formado al azar: todos han ganado un premio, que consiste en un viaje gratis a Europa en el mismo barco, que resulta ser el carguero Malcolm de la Magenta Star. ${ }^{14}$ En la estructura introduce una novedad las meditaciones de uno de los personajes, Persio, dispersas a través de la novela, dividida en tres días enmarcados por un Prólogo y un Epílogo. Las meditaciones, numeradas A, B, C. etc. y sin distribución regular dentro de los capítulos, nos hacen recordar los pasajes liricos intercalados por Baroja en la novela Paradox Rey. La novela de Cortázar tiene un trasfondo realista; pero se introduce una nota de misterio: los personajes no pueden ir a las cámaras de popa. Así, logra - Cortázar unir dos corrientes narrativas, la fantástica y la realista, y por

13 "Julio Cortázar por él mismo", Disco AMB, Discografía 123-25. Grabado en París en febrero del 1970.

14 Julio Cortázar, Los premios (Buenos Aires: Sudamericana, 1960). Citamos por la 10a. ed. (1970). Los antecedentes de esta estructura narrativa los encontramos en Conrad y Baroja, citados en la p. 43; la norteamericana Katherine Anne Porter usó la misma fotma en la novela Ship of Fools, publicada en 1962 pero que se comenzó a escribir veinte años antes. 
eso esta obra es significativa dentro del desarrollo de la nueva novela. En la nota final dice el autor: "También quisiera decirle [¿al lector?], tal vez curándome en salud, que no me movieron intenciones alegóricas y mucho menos éticas" (p. 427). Como la crítica ha insistido en la interpretación alegórica, Cortázar se ha visto obligado a reiterar su intención primera; en 1967, en una carta a García Canclini, le dice: "Es. cribí la novela sin la menor intención. Realmente la escribíl para divertirme, sin ironía ni amargura ni llamadas de atención. Es evidente que, por debajo, los temas simbólicos, los arquetipos que me rondan, se fueron abriendo paso. Si eso pusiera algo así como intenciones profundas o sublimadas, entonces si es obvio que esas intenciones existieron. Pero esa novela no fue escrita con el estado de ánimo que dictó, por ejemplo, Adán Buenosayres. Creo que no lo convenceré, como no he convencido a ningún crítico con esa nota final. $Y$ sin embargo, me aferro a ella porque lo que dice es exacto, aunque el resultado haya sido otro" (p. 38, nota).

Después de un interludio, representado por las Historias de cronopios y de famas (1962), ingeniosos relatos en los que vuelve al reino de lo irreal, Cortázar sorprende al mundo de las letras con Rayuela (1963), su obra máxima y con la cual la nueva novela hispanoamericana obtiene su más alto nivel. No es, por supuesto, la primera novela importante publicada por un hispanoamericano, como dijera un crítico inglés. ${ }^{15}$ Pero no cabe duda de que las contribuciones al desarrollo del arte de novelar son de gran magnitud. Enumeremos las más importantes. La estructura abierta es, por supuesto, lo que más llamó la atención: se incita al lector a que participe en la creación de la obra y a que se convierta en cómplice. En el capítulo 79 encontramos una "Nota pedantísima" atribuida a Morelli en torno a la naturaleza de la novela. Intentar, dice, "un texto que no agarre al lector pero que lo vuelva obligadamente cómplice al murmurarle, por debajo del desarrollo convencional, otros rumbos más esotéricos". ${ }^{16} \mathrm{Y}$ también: "La novela se contenta con un orden cerrado. Resueltamente en contra, buscar también aquí la apertura y para eso cortar de raíz toda construcción sistemática de caracteres y situaciones. Método: la ironia, la autocrítica incesante, la incongruencia, la imaginación al servicio de nadie" (Ibid.). En Rayuela, de la novela tradicional no queda ni la sombra. No menos importante que la novedosa estructura ( $y$ tal vez esto sea la mayor contri-

15 En The Times Literary Supplement, Londres (14 de nov. de 1968). 452.

16 Julio Cortázar, Rayuela 3a ed. (Buenos Aires: Sudamericana, 1966), p. 
bución), es el ataque al lenguaje trivial —al cliché, a la frase hecha, al dicho hueco de significado, a la muletilla mental- y, por extensión, al orden establecido que se refleja en el lenguaje anquilosado que predomina en la sociedad y sobre todo en la clase media. Como reacción extrema a lo establecido llega a inventar un lenguaje sintético, el gliglico, que en sus conversaciones usan Oliveira y la Maga; y el capítulo 68 es una verdadera jitanjáfora en prosa. La influencia' del estilo que en Rayuelá logró forjar Cortázar ha cambiado la trayectoria de la novela hispanoamericana. La siguiente cita lo comprueba: "Con posteridad, pues, a la publicación de Rayuela en 1963, aparecen en Hispanoamérica una serie de novelas en las que lo puramente novelesco es casi inexistente, en que se renuncia a todos los valores clásicos, en que se rompe con toda definición de género en cuanto formas ajustadas a un orden de representaciones y la novela resulta así pura y simple manifestación de un lenguaje que no tiene otra ley que afirmar su existencia, que no hace sino desdoblarse sobre sí mismo como si su discurso no pudiera' tener por contenido más que comentar su propia forma, o bien, que busca encontrar en el acto de la escritura la esencia de toda obra literaria":17 Excelentes ejemplos de este tipo de novela serían Farabeuf (1965) de Salvador Elizondo, Paradiso (1966) de Lezama Lima, Tres tristes tigres (1967) de Cabrera Infante y De donde son los cantantes (1967) de Sarduy. Nos queda por añadir que en Rayzela encontramos otro elemento, raro en la narrativa hispanoamericana, no menos impor: tante: el humor. La descripción del concierto de madame Berthe Trépat, la "gran fórmula en pro de la paz del mundo" del loco genial Ceferino Piriz, los riesgos del cierre relámpago, las cartas del Lic. Juan Cuevas son páginas memorables por el sentido del humor con que se las ha trazado.

El cuarto elemento importante que encontramus en Rayuela es el temático, que gira en torno a la búsqueda del significado de la existencia. Con razón ha dicho el crítico y novelista C. D. B. Bryan acerca de esta novela genial: "Hopscotch is the most significant novel I have read, and one to which I return from time to time. No other novel by a living author has influenced me as much, nor has interested and enchanted me more than Hopscotch. No other novel has explored so fully and completely man's compulsion to explain human life, to seek its meaning, to callenge its mysteries. No other novel of late has devoted so much love and attention to the whole range of the writer's art". ${ }^{18}$

17 Angela Dellepiane, "La novela del lenguaje", en Donald W. Bleznick, ob. cit., $\mathrm{pp}, 63-75$.

${ }_{18}$ The New Republic (13 de abril de 1966). 
Al autor de una gran novela, desde Cervantes hasta Rulfo, Garcia Márquez y Cortázar, les es dificil superarse. En las obras posteriores a Rayuela (Todos los fuegos el fuego, 1966; La vuelta al dia en ocbenta mundos, 1967; 62. Modelo para armar, 1968; Libro de Manuel 1973) encontramos páginas brillantes, estructuras originales, personajes sumamente bien delineados y vívidas situaciones; pero en ninguna de ellas se logra superar lo of recido en Rayuela. No queremos insinuar que el genio de Cortázar se haya agotado. Mañana puede sorprendernos con otra gran novela. Y si no lo hace, lo que ya ha publicado es suficiente para concederle lugar preeminente entre los narradores, no sólo de Hispanoamérica, sino del mundo entero.

LUIS LEAL

University of Illinois, Urbana 
